\title{
DESEMPENHO DE GENÓTIPOS DE AMENDOIM NO TRIÂNGULO MINEIRO
}

Marcos Guido Domenici ${ }^{1}$; Aline Oliveira Zacharias ${ }^{2}$; Eduardo Henrique Guiraldelli ${ }^{3}$; Jair Heuert ${ }^{4}$; Taís de Moraes Falleiro Suassuna ${ }^{5}$

${ }^{1}$ Engenheiro Agrônomo, Terranuts Agroindustrial S.A. Dumont-SP (Apresentador do Trabalho) marcos.domenici@terranuts.com.br; ${ }^{2}$ Engenheira Agrônoma, Secretaria de Inovação e Negócios da Embrapa Escritório do Triângulo Mineiro, Uberlândia-MG; ${ }^{3}$ Técnico Agrícola, Terranuts Agroindustrial S.A. Dumont-SP; ${ }^{4}$ Engenheiro Agrônomo, Técnico da Embrapa, Santo Antônio de Goiás-GO, jair.heuert@embrapa.br; ${ }^{5}$ Engenheira Agrônoma, Pesquisadora da Embrapa, Santo Antônio de Goiás-GO, tais.suassuna@embrapa.br.

RESUMO: A região do Triângulo Mineiro se destaca no cultivo de amendoim, sendo responsável por 96,84\% da produção do estado de Minas Gerais. Este trabalho foi instalado em Frutal-MG e avaliou três linhagens desenvolvidas pelo programa melhoramento genético da Embrapa (13-374 OL, 13-413 OL e 13-425 OL) e duas cultivares (Granoleico e IAC 505) já conhecidas dos produtores da região. O ensaio seguiu o delineamento de blocos casualizados e foi avaliada a produtividade, massa de 100 grãos e severidade por cercosporioses. As três linhagens (13-374 OL, 13-413 OL e 13-425 OL) tiveram um excelente desempenho em produtividade, já os valores de severidade se equivaleram ao controle IAC 505. A linhagem 13-374 OL se destacou pela maior massa de 100 grãos.

Palavras chaves: Arachis hypogaea L., cultivares, melhoramento genético.

\section{INTRODUÇÃO}

A região do Triângulo Mineiro compreende o espaço geográfico localizado entre os rios Grande e Paranaíba, no extremo Oeste do estado de Minas Gerais. A região vem se destacando, sendo responsável por $90,04 \%$ da área e $96,84 \%$ da produção de amendoim do estado ( 9.080 toneladas) e produtividade média de $3.847 \mathrm{~kg} / \mathrm{ha}$ (IBGE/LSPA Dezembro/2017, SEAPA-MG, 2018).

A estratégia para adequar um sistema produtivo do amendoim é realizar ensaios com novos genótipos para selecionar as melhores características de desenvolvimento, produtividade, qualidade do grão e observando a severidade frente às principais doenças. Essas características são determinantes para fazer a escolha de genótipos que se adaptam as singularidades climáticas de cada região do país. (VASCONCELOS et al., 2015).

$\mathrm{O}$ amendoim cultivado na região do Triângulo Mineiro ocupa áreas de renovação de canavial e também áreas de culturas anuais. A produção é transportada para estado de São Paulo, destinada às indústrias de doces de Dumont-SP ou para uma cooperativa em Jaboticabal-SP. Este mercado exige vagens e sementes com padrão "Runner", que apresentam elevado rendimento industrial, elevado teor de ácido oleico (alto oleico), sendo também o tipo predominante no mercado de exportação de amendoim. 
O presente trabalho teve como objetivo avaliar produtividade, massa de 100 grãos e severidade da mancha preta nas linhagens tipo Runner alto oleico, desenvolvidas pelo programa de melhoramento genético da Embrapa, na região do Triângulo Mineiro.

\section{MATERIAS E MÉTODOS}

O ensaio foi instalado em Frutal-MG, na Fazenda Natividade, no dia 24 de novembro de 2017. Todos os tratos culturais seguiram as recomendações técnicas. Foi avaliado 5 genótipos, sendo três linhagens desenvolvidas pela Embrapa (13-374 OL, 13-413 OL e 13-425 OL) e duas cultivares (IAC 505 e Granoleico), utilizadas pelos produtores da região. Cada parcela era composta por duas linhas de 3 metros, correspondendo a uma área útil de $5,4 \mathrm{~m}^{2}$, com 4 repetições cada tratamento. O estande de plantas do ensaio ficou com uma média de 16 plantas por metro linear. A colheita foi realizada aos 130 dias após a semeadura.

A severidade da mancha preta do ensaio foi avaliada usando a escala diagramática da incidência da mancha preta com notas de 1-9. (SUBRAHMANYAM et. al., 1982).

Os dados foram analisados via modelos mistos (REML BLUP), visando obter os valores genotípicos para avaliar o desempenho das linhagens, além de parâmetros de acurácia e precisão dos ensaios, como recomendado por RESENDE \& DUARTE (2007).

\section{RESULTADOS E DISCUSSÃO}

Foi observada a diferença entre os tratamentos para todas as variáveis (Tabela 1). A severidade foi intensa e com desfolha no terço inferior ocasionada pela mancha preta (Cercosporidium personatum), embora o manejo de fungicidas tenha sido realizado conforme as recomendações. A cultivar Granoleico foi a mais afetada com a maior severidade com nota 8,5. As linhagens (13-374 OL, 13-413 OL e 13-425 OL) mantiveram nota semelhante a cultivar IAC 505.

A produtividade média geral do ensaio foi $6.352,39 \mathrm{~kg}$ em casca ha ${ }^{-1}$. As três linhagens ficaram acima da média, mostrando a sua adaptabilidade para as condições edafoclimáticas dessa região. Os controles tiveram uma produtividade abaixo da média; a cultivar IAC 505 ficou $6.010,9 \mathrm{~kg}$ em casca ha ${ }^{-1}$ e Granoleico ficou 5.404,9 $\mathrm{kg}$ em casca ha ${ }^{-1}$. 
16 e 17 de agosto de 2018, centro de convenções da FCAV/UNESP - Câmpus de Jaboticabal, SP

Tabela 1 - Avaliação de genótipos de amendoim em Frutal-MG; safra 2017-18

\begin{tabular}{|c|c|c|c|c|}
\hline Genótipo & $\begin{array}{c}\text { Produtividade } \\
\text { (Kg/ha-1 em casca) }\end{array}$ & $\begin{array}{c}\text { Massa de } 100 \\
\text { Grãos (g) (1) }\end{array}$ & Severidade & $\begin{array}{l}\text { Produtividade } \\
\text { Sacas/alqueire }\end{array}$ \\
\hline $13-425 \mathrm{OL}$ & $6.897,1$ & 74,0 & 7,7 & 667,6 \\
\hline $13-413 \mathrm{OL}$ & $6.866,9$ & 76,3 & 8,0 & 664,7 \\
\hline $13-374 \mathrm{OL}$ & $6.582,2$ & 86,1 & 7,7 & 637,1 \\
\hline IAC 505 & $6.010,9$ & 73,6 & 7,7 & 581,7 \\
\hline Granoleico & $5.404,9$ & 76,1 & 8,5 & 523,1 \\
\hline Média & $6.352,4$ & 77,2 & 7,9 & - \\
\hline $\mathrm{CV}(\%)(1)$ & 8,6 & 0,65 & 1,99 & - \\
\hline $\mathrm{F}(2)$ & $7,4 *$ & $407,5^{*}$ & $20,6^{*}$ & - \\
\hline Acurácia & 0,9 & 0,9 & 0,9 & - \\
\hline
\end{tabular}

Maior tamanho de sementes (massa de 100 grãos) foi observado na linhagem 13-374 OL, com 86,1 g. A linhagem 13-413 OL se assemelhou ao tamanho da cultivar comercial Granoleico e a 13-425 OL possui um tamanho semelhante a cultivar comercial IAC 505. Os genótipos desenvolvidos pela Embrapa podem se adequar as diversas exigências de tamanho de grãos exigidos pelo mercado.

\section{CONCLUSÃO}

As maiores produtividades foram observadas nas linhagens 13-425 OL, 13-413 OL e 13-374 OL, desenvolvidas pela Embrapa.

A severidade das três linhagens desenvolvidas pela Embrapa ficou semelhante ao controle IAC 505 .

As três linhagens se diferenciaram quanto à massa de 100 grãos, podendo se adequar as variadas exigências de mercado quanto ao tamanho.

\section{AGRADECIMENTOS}

Os autores agradecem ao produtor Marco Aurélio Campos, pela colaboração em todos os momentos da condução do ensaio.

\section{REFERENCIAS BIBLIOGRAFICAS}

IBGE, Levantamento Sistemático da Produção Agrícola, Bancos de tabelas estatísticas. Disponível: https://sidra.ibge.gov.br/home/lspa/brasil, acessado em: 11/06/2018.

RESENDE, M.D.V.; Duarte, J.B. (2007) Precisão e controle de qualidade em experimentos de avaliação de cultivares. Pesquisa Agropecuária Tropical 37: 182-194.

SEAPA-MG - Secretaria de Estado de Agricultura, Pecuária e Abastecimento de Minas GeraisSubsecretaria do Agronegócio. AMENDOIM. Abril de 2018. Disponível: 
http://www.reformaagraria.mg.gov.br/images/documentos/perfil_amendoim_abr_2018[1].pdf, acessado em: 02/06/2018.

VASCONCELOS, F.M.T.; VASCONCELOS, R.A.; LUZ, L.N.; CABRAL, N.T.; OLIVEIRA JÚNIOR, J.O.L.; SANTIAGO, A.D.; SGRILLO, E.; FARIAS, F.J.C.; MELO FILHO, P.A.; SANTOS, R.C. Adaptabilidade e estabilidade de genótipos eretos de amendoim cultivados nas regiões Nordeste e Centro-Oeste. Ciência Rural. Santa Maria, vol.45, n.8, p.1375-1380, 2015.

SUBRAHMANYAM, P.; MCDONALD, D.; GIBBONS, R. W.; NIGAM, S. N.; NEVILL, D.J. Resistance to rust and late leaf spot diseases in some genotypes of Arachis hypogaea. Peanut Science, v.9, p.9-14, 1982. 